\title{
In memory of a friend and distinguished scholar: Luigi Orsenigo (1954-2018)
}

\author{
Giovanni Dosi ${ }^{1} \cdot$ Franco Malerba $^{2}$
}

It is with infinite and deep sorrow that we have to announce that our friend, colleague and brother Luigi (Gigi) Orsenigo passed away on April 30, 2018. We will miss him incredibly. He will always be irreplaceable.

Gigi has been among the most important scholars at international level in the fields of innovation and industrial dynamics and more generally in evolutionary economics. Indeed, he should be considered among the founders of the economics of innovation itself since his doctoral year at the Science Policy Research Unit (SPRU) of the University of Sussex, in the early 80s. In his (too short) scientific career he has dealt with depth and originality a variety of themes from the emergence of the biotechnology industry to the micro-foundations of macroeconomic dynamics, from the role of intellectual property rights to national and sectoral systems of innovation, and many others.

At least equally important, Gigi has always tried to join scientific research and civil concerns, always aware of the social consequences of economic and innovation policies.

This is a huge loss for the whole international community.

Franco Malerba

franco.malerba@unibocconi.it

Giovanni Dosi

giovanni.dosi@santannapisa.it

1 Scuola Superiore S. Anna, Pisa, Italy

2 Bocconi University, Milan, Italy 